\title{
The Canadian National EMS Research Agenda: a mixed methods consensus study
}

\author{
Jan L. Jensen, MAHSR, ACP**; Blair L. Bigham, MSc, ACP ${ }^{\ddagger \S}$; lan E. Blanchard, MSc, EMT-P ${ }^{\| \uparrow ; ~}$ \\ Katie N. Dainty, $\mathrm{PhD}^{\ddagger}$; Doug Socha, BSc, $\mathrm{PCP}^{\#}$; Alix Carter, MD, $\mathrm{MPH}^{*}{ }^{\dagger}$; \\ Lawrence H. Brown, PhD, MPH\&TM, EMT-P**; Andrew H. Travers, MD, MSc ${ }^{*}$; \\ Alan M. Craig, MScPL, $\mathrm{ACP}^{\dagger+}$; Ryan Brown, BSc, $\mathrm{PCP}^{*}$; Laurie J. Morrison, $\mathrm{MD} \mathrm{MSc}^{\S}$
}

\section{ABSTRACT}

Introduction: Research is essential for the development of evidence-based emergency medical services (EMS) systems of care. When resources are scarce and gaps in evidence are large, a national agenda may inform the growth of EMS research in Canada. This mixed methods consensus study explores current barriers and existing strengths within Canadian EMS research, provides recommendations, and suggests EMS topics for future study.

Methods: Purposeful sampling was employed to invite EMS research stakeholders from various roles across the country. Study phases consisted of 1) baseline interviews of a subsample, 2) roundtable discussion, and 3) an online Delphi survey, in which participants scored each statement for importance. Consensus was defined a priori and met if $80 \%$ scored a statement as "important" or "very important." Results: Fifty-three stakeholders participated, representing researchers $(37.7 \%)$, EMS administrators $(24.6 \%)$, clinicians/ providers $(20.7 \%)$, and educators $(17.0 \%)$. Participation rates were as follows: interviews, 13 of $13(100 \%)$; roundtable, 47 of $53(89 \%)$; survey round 1, 50 of $53(94 \%)$; survey round 2 , 47 of $53(89 \%)$; and survey round 3,40 of $53(75 \%)$. A total of 141 statements were identified as important: 20 barriers, 54 strengths/opportunities, 31 recommendations, and 36 suggested topics for future research. Like statements were synthesized, resulting in barriers $(n=10)$, strengths/opportunities $(n=24)$, and recommendations $(n=19)$, which were categorized as time, opportunities, and funding; education and mentorship; culture of research and collaboration; structure, process, and outcome of research; EMS and paramedic practice; and the future of the EMS Research Agenda.

Conclusion: Consensus-based key messages from this agenda should be considered when designing, funding, and publishing EMS research and will advance EMS research locally, regionally, and nationally.

\section{RÉSUMÉ}

Introduction: La recherche est essentielle à I'organisation de systèmes de services médicaux d'urgence (SMU), fondés sur des données probantes. Lorsque les ressources sont rares et qu'il y a des lacunes importantes en matière de données, l'élaboration d'un programme national peut aiguiller la croissance de la recherche sur les SMU au Canada. L'étude de consensus décrite ici, qui associe différentes méthodes, a fait état des obstacles et des forces qui existent actuellement au sein de la recherche sur les SMU au Canada, contient des recommandations et présente des sujets de recherche possibles en matière de SMU.

Méthode: Nous nous sommes appuyés sur un échantillon choisi à dessein pour inviter différents intervenants en recherche sur les SMU, selon leur rôle et leur provenance dans le pays. Les phases de l'étude consistaient en 1) des entrevues exploratoires d'un sous-groupe; 2 ) une table ronde; et 3) une enquête menée selon la méthode Delphi dans laquelle les participants évaluaient l'importance de chacun des énoncés. La définition de consensus a été établie au préalable et il y avait consensus si $80 \%$ des participaient considéraient un énoncé comme " important " ou " très important".

Résultats: Cinquante-trois intervenants, représentant des chercheurs $(37.7 \%)$, des administrateurs de SMU $(24.6 \%)$, des cliniciens ou des fournisseurs de soins $(20.7 \%)$, et des éducateurs $(17.0 \%)$ ont participé à l'étude. Les taux de participation se sont établis comme suit: entrevues: 13 sur $13(100 \%)$; table ronde: 47 sur $53(89 \%)$; 1 er tour d'enquête: 50 sur $53(94 \%)$; 2e tour d'enquête: 47 sur $53(89 \%)$; 3e tour d'enquête: 40 sur 53 (75\%). Au total, 141 énoncés ont été jugés

*Emergency Health Services, Dartmouth, NS; †Division of EMS, Dalhousie University, Halifax, NS; †Rescu, Li Ka Shing Knowledge Institute, St. Michael's Hospital, University of Toronto, Toronto, ON; §York Region Emergency Medical Services, Sharon, ON; || Emergency Medical Services, Alberta Health Services, Calgary, AB; \|Department of Community Health Sciences, Faculty of Medicine, University of Calgary, Calgary, AB; ๆHastings-Quinte EMS, Hastings County, ON; **School of Public Health, Tropical Medicine and Rehabilitation Sciences, James Cook University, Queenland, Australia; ††Toronto Emergency Medical Services, Toronto, ON.

Correspondence to: Jan L. Jensen, 239 Brownlow Avenue, Suite 300, Dartmouth, NS B3B 2B2; jljensen@dal.ca.

This article has been peer reviewed. 
importants: 20 obstacles, 54 forces ou possibilités, 31 recommandations, et 36 sujets possibles de recherche. Ces énoncés ont par la suite été groupés, ce qui a donné lieu à un nombre réduit d'obstacles $(n=10)$, de forces ou de possibilités ( $n=24)$, et de recommandations $(n=19)$; puis à leur répartition dans différentes catégories: temps, possibilité, financement; enseignement/formation, et mentorat; culture de la recherche et de la collaboration; structure, processus, et recherche sur les résultats; SMU et pratique paramédicale; avenir du programme de recherche sur les SMU.
Conclusions: Les messages clés consensuels, découlant de la démarche devraient être pris en considération lorsque viendra le temps de concevoir et de financer des études sur les SMU et d'en publier les résultats; ils feront également progresser la recherche en matière de SMU à l'échelle locale, régionale, et nationale.

Keywords: agenda, consensus, emergency medical services, mixed methods, research
Over the last three decades, emergency medical services (EMS) systems have developed from basic transport services to systems of advanced out-ofhospital clinical care. ${ }^{1,2}$ Concerns have been expressed that limited science exists to support the changes in EMS and that more research is needed. Some research has not been effectively translated into practice, ${ }^{3-7}$ whereas in any other areas of EMS, there continues to be few empirical data available. ${ }^{8}$ In response, EMS organizations across Canada, including a national association, have identified the development of research as a priority. ${ }^{9}$

Several countries have undertaken development of a national research agenda with the goal of advancing EMS research. In Australia, a concerted effort in 2002 to identify research priorities, ways to encourage research, and the roles different organizations have to play in conducting research systematically identified areas for improvement. ${ }^{10}$ In the United States, the National EMS Research Agenda identified five key barriers to the development of EMS research and made eight recommendations but did not identify topics requiring further study. ${ }^{11-14}$ The Institute of Medicine agreed that there is a lack of evidence to support EMS practice and cited the US agenda in its recommendations for improving EMS systems. ${ }^{15}$ Subsequent advances that can be linked to the recommendations of the US EMS research agenda include research fellowships at the National Registry for Emergency Medical Technicians, ${ }^{16}$ a recent call for proposals to develop national evidence-based EMS guidelines, ${ }^{17}$ and the publication of a guide to EMS research. ${ }^{18}$ In the United Kingdom, a research agenda for prehospital care was completed, which reviewed the available evidence and exposed gaps in research. ${ }^{19}$ In Ireland, an EMS research agenda identified several recommendations for change but did not systematically identify barriers or facilitators, nor did it determine topics that should be the focus of further study. ${ }^{20}$ There are limits in extrapolating these international agendas to the Canadian landscape due to inherent heterogeneity in the type and breadth of EMS systems between countries. It is the unique constellation of factors that make up an EMS system, along with the maturity of the research enterprise, that influences the output of a research agenda. Setting differences in which Canadian EMS systems operate (i.e., the overall health care system, provider training, regulation, and geography), as well as differences in the maturation of Canadian EMS and EMS research compared to other countries, will produce a unique perspective on the development of a research agenda.

Little is known about barriers and unique enablers that may impact the growth and development of Canadian EMS research. The purpose of this study was to support and guide Canadian EMS research growth through the exploration of four objectives: 1) systematically determining the existing barriers to Canadian EMS research, 2) identifying current strengths and opportunities to conduct and use research in Canadian EMS, 3) making recommendations to facilitate the development of EMS research in Canada, and 4) identifying suggestions of topics for future study.

\section{METHODS}

The methodology for this project has been published in a separate article. ${ }^{21}$ In brief, this mixed methods study consisted of three study phases: 1) baseline qualitative interviews (reported separately (Developing a Canadian EMS research agenda: a baseline study), followed by a modified Delphi approach, which consisted of 2) an in-person facilitated roundtable discussion and 3) an online multiround quantitative Delphi consensus survey. ${ }^{22}$ 


\section{Sample}

Purposeful sampling was employed to recruit three to four EMS research stakeholders from a priori identified key categories derived from professional roles, organizations, and geographic regions. Stakeholder categories based on professional roles were paramedic researchers, EMS educators, EMS providers, EMS managers, EMS regulators, EMS physicians, and EMS physician researchers (see Table 1, (Developing a Canadian EMS research agenda: a baseline study). The term paramedic in this research agenda is inclusive of all levels of practicing paramedics in Canada (i.e., basic and advanced life support), and the term EMS administrators refers to both managers and regulators. One representative was recruited from each of the relevant national EMS organizations. Potential participants received a recruitment letter and were invited to participate in the roundtable and Delphi surveys. Willing volunteers provided written consent prior to the start of the study. The Capital District Health Authority Research Ethics Board (Halifax, NS) approved the study.

\section{Data collection and analysis}

\section{Roundtable}

Consensus building began with a 6-hour in-person roundtable session. Prior to the roundtable, participants were informed of the four study objectives (barriers, strengths and opportunities, recommendations, and suggested topics for future study). These were discussed in small facilitated groups, followed by large-group discussion, all moderated by a professional facilitator. Participants were purposefully placed into small groups, so each had a mix of stakeholders and geographic regions.

\section{Derivation of the quantitative Delphi survey tool} The Delphi survey was derived from unique statements recorded during the small-group sessions, in addition to personal perspectives recorded by participants on submitted individual worksheets. Statements were initially collated and summarized by four investigators (J.L.J., B.L.B., I.E.B., R.B.). The statements within each objective were categorized by best fit by two investigators (I.E.B. and L.H.B.) to six content areas, which were identified after the data were collected from the roundtable session: 1) time, opportunities, and funding; 2) education and mentorship; 3) culture of research and collaboration; 4) structure, process, and outcome of research; 5) EMS and provider practice; and 6) the future of the EMS research agenda. When there was disagreement on the assignment, a third investigator served as adjudicator (A.H.T.). The survey tool was pilot-tested by five researchers not associated with the study.

\section{Scoring the quantitative Delphi survey tool}

Participants scored the importance of each statement on a 5 -point Likert scale $(1=$ not important to $5=$ extremely important). Participants were encouraged to suggest new statements and provide comments. It was determined a priori that a statement would be declared "important" if it was rated as "important" or "extremely important" by at least $80 \%$ of participants who answered the question. Similarly, a statement was defined as "unimportant" if $80 \%$ of participants rated it as "not important" or "not very important." ${ }^{33,24}$ Statements that achieved consensus were removed from the Delphi survey for subsequent rounds. For the second and third rounds, a Microsoft Access (Microsoft Corporation, Redwood, CA) report was generated for each participant showing the mean scores and the participant's own score for each statement from the previous round. Participants were then able to consider their scoring within the context of other scores and rescore each statement or keep the score they originally assigned. ${ }^{25-27}$

\section{Conducting the survey}

An electronic survey tool (Opinio version 6.5.1, Objectplanet, Oslo, Norway) was used to deliver the survey. Each survey was open for 2 weeks, with reminder emails sent to nonresponders every 4 days, with a 2 -week gap between rounds to permit data analysis. The Delphi survey was designed to have a maximum of four rounds. Stopping rules were established a priori: evidence of respondent fatigue and a substantial decrease in new statements reaching consensus. ${ }^{22}$

\section{Data management}

Data were exported into Microsoft Excel. Participant characteristics, mean scores, and percent consensus were calculated after each round of circulation.

\section{Data triangulation}

We employed methodological triangulation, which is the application and combination of multiple research 
methodologies to study the same phenomenon..$^{28}$ Triangulation facilitates validation of data through cross-verification from more than two sources. In our study, we applied this approach to data from the interviews, roundtable discussion, and Delphi consensus survey. Emerging themes were analyzed for convergence, silence, and dissonance (J.L.J., K.N.D., I.E.B.). ${ }^{29,30}$

\section{RESULTS}

\section{Sample and response rate}

Fifty-three participants from across Canada took part, representing 10 of 13 Canadian provinces and territories. Each self-identified his or her professional designation as follows: 36 EMS providers, 16 physicians, and 1 nurse. The participants represented a cross section of roles, including 20 researchers, 12 EMS administrators, 11 physicians and EMS providers (i.e., they identified their primary role as clinical care), 9 educators, and 1 government emergency management administrator (Table 1). The group had a mean of 19 years of EMS experience (SD 8.9 years). All participants completed at least one phase of the study: 47 (89\%) attended the roundtable, 50 (94\%) participated in round 1 of the Delphi process, 47 (89\%) in round 2, and $40(75 \%)$ in round 3.

\section{Quantitative results}

At the roundtable, 289 unique statements were generated. The Delphi rounds contained 289, 247, and 221 statements, respectively; statements in which consensus was achieved were removed from subsequent rounds. In round 1, participants provided 78 free text comments, from which 18 new statements were added to the Delphi survey. In round 2, participants made 53 comments, which resulted in 13 new statements being added to the Delphi survey. The Delphi consensus survey was terminated following three rounds after assessment of stopping rules. Triangulation of qualitative interviews (ref to Developing a Canadian EMS research agenda: a baseline study), roundtable, and Delphi phases revealed high data convergence between the initial qualitative findings and the subsequent data gathered during the roundtable and Delphi survey. Additional themes that were not identified during the baseline interviews arose during the roundtable discussion.

\begin{tabular}{lc} 
Table 1. Characterisitics of those who participated in one or \\
more phases of the EMS Research Agenda study \\
\hline Characteristic & $n(\%)$ \\
\hline Participants & 53 \\
Type & \\
Paramedic & $35(66.0)$ \\
Physician & $16(30.2)$ \\
Paramedic and nurse & $1(1.9)$ \\
Nurse & $1(1.9)$ \\
Role & \\
Researcher & $17(32.0)$ \\
Educator & $9(17.0)$ \\
Researcher and educator & $3(5.7)$ \\
EMS manager & $10(18.9)$ \\
EMS regulator & $2(3.8)$ \\
Paramedic only & $5(9.4)$ \\
Physician only & $6(11.3)$ \\
Emergency management & $1(1.9)$ \\
administrator & \\
Location & \\
Alberta & $7(13.2)$ \\
British Columbia & $4(7.5)$ \\
Manitoba & $1(1.9)$ \\
New Brunswick & $3(5.7)$ \\
Newfoundland and Labrador & $1(1.9)$ \\
Nova Scotia & $9(17.0)$ \\
Northwest Territories & $0(0)$ \\
Nunavut Territory & $0(0)$ \\
Ontario & $22(41.5)$ \\
Prince Edward Island & $0(0)$ \\
Quebec & $4(7.5)$ \\
Saskatchewan & $1(1.9)$ \\
Yukon Territory & $1(1.9)$ \\
\hline EMS = emergency medical services. & \\
& \\
\hline &
\end{tabular}

These were found to be convergent with the consensus results, indicating high consistency across the data set as a whole.

A total of 141 statements achieved consensus as "important": 20 barriers, 54 strengths/opportunities, 31 recommendations, and 36 suggested topics for future study. No statements achieved consensus as "unimportant."

Twenty statements pertaining to barriers to Canadian EMS research were consolidated into 10 (Table 2). Fifty-four statements pertaining to strengths and opportunities were consolidated into 24 (Table 3). Participants achieved consensus on 36 topics that require increased research attention (Table 4). Thirty-one statements constituting recommendations for the future were consolidated into 19 (Table 5). 


\begin{tabular}{|c|c|}
\hline Content area & Barriers \\
\hline $\begin{array}{l}\text { Time, opportunities, } \\
\text { and funding }\end{array}$ & $\begin{array}{l}\text { 1. There are few funding sources for EMS research projects or for EMS systems to conduct research. } \\
\text { 2. There are very few EMS research jobs or little research salary support, and there is a lack of dedicated time for } \\
\text { EMS providers who are interested in conducting or assisting in research. }\end{array}$ \\
\hline $\begin{array}{l}\text { Education and } \\
\text { mentorship }\end{array}$ & $\begin{array}{l}\text { 3. There is a lack of baseline research knowledge among people who work in EMS (providers, physicians, and } \\
\text { others). Entry-to-practice paramedic programs often do not include an introduction to research course, and } \\
\text { research and evidence-based literacy have not been part of the NOCPs. } \\
\text { 4. There are few opportunities for research mentorships outside of fellowship programs for physicians. } \\
\text { 5. EMS services often do not support EMS providers in taking graduate education in research-related degrees. }\end{array}$ \\
\hline $\begin{array}{l}\text { Culture of research } \\
\text { and research } \\
\text { collaboration in EMS }\end{array}$ & $\begin{array}{l}\text { 6. There is little or no relationship between EMS services and academia, and governments, hospitals, } \\
\text { universities, and EMS services often do not work together to conduct studies. } \\
\text { 7. EMS research studies compete with operational and other priorities within the system, but a clear strategic } \\
\text { direction for EMS research does not exist, and EMS services do not include EMS research in their strategic } \\
\text { planning. } \\
\text { 8. EMS providers and managers are often not part of the design and planning phases of research studies. EMS } \\
\text { providers often do not understand the importance of studies, which can impact accurate data collection. }\end{array}$ \\
\hline $\begin{array}{l}\text { Structure, process, } \\
\text { and outcome }\end{array}$ & $\begin{array}{l}\text { 9. It can be difficult to obtain informed consent in clinical studies in the EMS setting. } \\
\text { 10. EMS data are sometimes not clean (e.g., data points are not well defined, not all users understand what } \\
\text { information to enter), and there are inconsistencies between how different services measure, collect, and } \\
\text { analyze their data. EMS data sets are difficult to link with hospital data to obtain outcome data and to conduct } \\
\text { population/epidemiologic studies. }\end{array}$ \\
\hline
\end{tabular}

EMS $=$ emergency medical services; $\mathrm{NOCP}=$ National Occupational Competency Profile.

\section{DISCUSSION}

Participants who were representative of the functional and geographic landscape of EMS in Canada contributed consistently to every study phase and reached consensus on many statements. The broad range of unique statements made demonstrates the complexity of the topic of EMS research and will be helpful in developing a stronger EMS research enterprise in Canada.

In terms of time, opportunities, and funding, participants perceive EMS-specific funding opportunities as limited, as well as research positions and opportunities for providers to develop their own research ideas. In some locations, strong collaborations between EMS systems and universities specializing in prehospital research exist, and there are some examples of success, such as obtaining funding for large studies and building incentives into EMS operations contracts to conduct research.

For education and mentorship, participants stated that EMS providers often lack foundational knowledge on research and critical appraisal, which has not typically been taught in entry-to-practice paramedic programs. Few EMS providers or EMS physicians pursue research training or graduate studies, possibly in part because of a perceived lack of opportunities.
However, participants stated that more EMS providers obtain undergraduate degrees, and some education institutions offer undergraduate paramedic degrees, acceptable for admission to graduate programs. Participants also identified several universities with strong prehospital research programs and mentors, which have led to several EMS researchers achieving university appointments, research grants, and peer-reviewed publications. In some EMS systems, research mentorship has started at the individual project level by hiring providers into research assistant or coordinator roles and guiding them through the research process, essentially providing on-the-job training in research.

Related to the culture of research and collaborations, participants felt that EMS systems do not value research as important as research seems to compete with operations and other priorities. A culture of appreciation for research is needed to ensure strategic planning of EMS operations and that funding includes resources and a willingness to do research and partnerships between EMS systems and academia are pursued to facilitate high-quality research. This type of culture may lead to improved research participation by providers, including enrolment, protocol compliance, data quality, and faster translation of evidence into practice. 


\begin{tabular}{|c|c|}
\hline Content area & Strengths and opportunities \\
\hline \multirow{5}{*}{$\begin{array}{l}\text { Time, opportunities, } \\
\text { and funding to } \\
\text { conduct research }\end{array}$} & $\begin{array}{l}\text { 1. Large EMS systems can leverage government support for EMS research. Regulators can include incentives and } \\
\text { performance measures in operator contracts related to research. }\end{array}$ \\
\hline & 2. Large EMS research studies have acquired stable research funding. \\
\hline & $\begin{array}{l}\text { 3. The field of health services research is growing; funding is available to conduct research on health systems and } \\
\text { policy. Existing partnerships can be capitalized on to do this type of research in EMS. }\end{array}$ \\
\hline & $\begin{array}{l}\text { 4. There are many research questions to ask in EMS: the EMS patient population is quite varied (e.g., age, location, } \\
\text { illness, or injuries), certain aspects of EMS have not been well studied (e.g., EMS communications centres), and the } \\
\text { health system is under pressure, leading to reevaluation of service delivery. }\end{array}$ \\
\hline & $\begin{array}{l}\text { 5. In some locations, partnerships between EMS services and universities have been established to conduct research. } \\
\text { 6. Some EMS systems have a researcher on staff. }\end{array}$ \\
\hline \multirow[t]{5}{*}{$\begin{array}{l}\text { Education and } \\
\text { mentorship }\end{array}$} & $\begin{array}{l}\text { 7. A national standard for paramedic education exists, and an opportunity exists to leverage more research } \\
\text { competencies in the NOCP and future national examination. EMS educators can be trained in the fundamentals of } \\
\text { research, which they can teach their students. Colleges and paramedic training schools have the opportunity to } \\
\text { encourage research. }\end{array}$ \\
\hline & $\begin{array}{l}\text { 8. Paramedic training programs are increasingly collaborating with universities, and more degree programs are under } \\
\text { development. Research programs and courses specializing in EMS exist in Canada. }\end{array}$ \\
\hline & 9. EMS providers are obtaining more training and higher education than ever before. \\
\hline & $\begin{array}{l}\text { 10. High-quality graduate research degrees are offered at Canadian universities, and student research grants are } \\
\text { available. }\end{array}$ \\
\hline & $\begin{array}{l}\text { 11. There are established EMS research leaders who provide an opportunity for research mentorship for EMS } \\
\text { providers, managers, physicians, and others (such as by obtaining grant funding to hire EMS providers to work on } \\
\text { studies). }\end{array}$ \\
\hline \multirow{3}{*}{$\begin{array}{l}\text { Culture of research } \\
\text { and research } \\
\text { collaboration in } \\
\text { EMS }\end{array}$} & $\begin{array}{l}\text { 12. EMS research provides opportunities to collaborate with other disciplines (such as business, engineering, and social } \\
\text { sciences) and among existing EMS research centres and national organizations/associations. }\end{array}$ \\
\hline & 13. Positive experiences with one research study lead to other research studies. \\
\hline & 14. EMS providers and physicians already have good interdisciplinary collaboration. \\
\hline \multirow[t]{6}{*}{$\begin{array}{l}\text { Structure, process, } \\
\text { and outcome }\end{array}$} & $\begin{array}{l}\text { 15. There have been milestones in Canadian EMS research that have helped to move EMS research forward, such as } \\
\text { success in changing legislation restrictive to EMS and EMS research, large studies, and international EMS research } \\
\text { consortiums. }\end{array}$ \\
\hline & 16. EMS research committees that evaluate and coordinate EMS research projects are becoming more prevalent. \\
\hline & $\begin{array}{l}\text { 17. Some EMS systems collect data in the same way, including how data are defined and analyzed, and there is a } \\
\text { movement to create a national set of standard data definitions. This allows for EMS data sets to be consolidated } \\
\text { and stored in research registries to increase the statistical power of studies. Some EMS systems already have } \\
\text { linkages with hospitals for some outcome data (such as ST elevation myocardial infarction). }\end{array}$ \\
\hline & $\begin{array}{l}\text { 18. Many EMS services use electronic charting, including computer-aided dispatching, patient care charting, and } \\
\text { biometric monitoring, which can allow for real-time data analysis and reporting. Performance-based EMS contracts } \\
\text { require EMS operators to collect data. }\end{array}$ \\
\hline & 19. EMS researchers can use existing uniform data sets (such as the Canadian Institute for Health Information). \\
\hline & 20. EMS-specific evidence repositories exist, and research articles can be found online through Web-based databases. \\
\hline \multirow[t]{4}{*}{$\begin{array}{l}\text { EMS and paramedic } \\
\text { practice }\end{array}$} & $\begin{array}{l}\text { 21. In many locations in Canada, EMS regulation is moving to a provincial or regional level, which increases } \\
\text { standardization. }\end{array}$ \\
\hline & 22. EMS providers generally comply with protocols and can quickly adopt clinical research protocols. \\
\hline & $\begin{array}{l}\text { 23. The EMS setting is unique: paramedics are some of the few health care providers that have direct access to } \\
\text { patients in their home environments. The public generally considers EMS providers to be trusted professionals. }\end{array}$ \\
\hline & $\begin{array}{l}\text { 24. As the identity of EMS providers evolves, evidence is needed to guide the development of EMS protocols and } \\
\text { guidelines, especially for new and alternative EMS programs and scopes of practice, such as community/extended } \\
\text { care paramedic programs. }\end{array}$ \\
\hline
\end{tabular}

EMS data were identified as important to structure, process, and outcome yet were viewed to be of variable quality and difficult to link to other data sets to measure outcomes. Data quality was seen as improving, with an increase in computerized dispatch and electronic charting systems, many of which can include biometric data uploaded from defibrillators. In several locations, EMS research committees that evaluate and coordinate EMS research projects are becoming more prevalent, which may help improve EMS research strategic planning, provide better study designs, reduce the time it takes to start projects and 


\begin{tabular}{|c|c|}
\hline Content area & Topic for future study \\
\hline Clinical & $\begin{array}{l}\text { Links to clinical outcome data (including hospital, medical examiner) } \\
\text { Implementation of evidence-based protocols (such as Canadian C-spine Rule) } \\
\text { Clinical errors } \\
\text { Use of research evidence to create clinical protocols/guidelines } \\
\text { Clinical outcomes survival and other outcome measures } \\
\text { Sepsis } \\
\text { Clinical prediction rules/decision rules } \\
\text { Paramedic clinical decision making } \\
\text { Geriatric care } \\
\text { Respiratory distress (interventions such as continuous positive airway pressure) } \\
\text { Data collection and definitions }\end{array}$ \\
\hline $\begin{array}{l}\text { Health services/ } \\
\text { systems }\end{array}$ & $\begin{array}{l}\text { Destination decisions, nontransport, and alternatives to referrals by EMS providers } \\
\text { Regionalization of care for specific conditions in Canada (e.g., stroke, ST elevation myocardial infarction, sepsis, trauma) } \\
\text { Role of EMS in health protection and promotion } \\
\text { Cost-effectiveness of specific EMS programs (e.g., helicopter EMS, community paramedicine) } \\
\text { Deployment/system status management } \\
\text { ED overcrowding and ambulance offload delay time interval standards, interventions } \\
\text { Extended scope/community paramedicine programs } \\
\text { Triage by EMS providers } \\
\text { Best placement of advanced/basic crews (rural v. urban) } \\
\text { The role of the paramedic in various health settings }\end{array}$ \\
\hline Education & $\begin{array}{l}\text { Advanced decision-making training } \\
\text { Evidence-based practice/critical analysis training } \\
\text { Knowledge translation in EMS } \\
\text { Communication skills training } \\
\text { High-fidelity simulation } \\
\text { Competency assessment/testing }\end{array}$ \\
\hline Safety & $\begin{array}{l}\text { Most common errors, errors with biggest impact on safety and clinical outcome } \\
\text { Error, adverse event reporting } \\
\text { Transfer of care/information loss in handover } \\
\text { System interventions to improve patient and provider safety } \\
\text { Ergonomics, lifting, equipment design } \\
\text { Paramedic injury (including injury prevention programs) }\end{array}$ \\
\hline $\begin{array}{l}\text { Professional } \\
\text { development }\end{array}$ & $\begin{array}{l}\text { Maintenance of competence } \\
\text { How to conduct high-quality research in EMS } \\
\text { Using research to inform policy and nonclinical decisions }\end{array}$ \\
\hline
\end{tabular}

coordinate timing of similar studies, and foster collaborations.

Participants strongly supported evidence-based clinical practice and operations in EMS. Although great advances have been made in Canadian EMS research, little evidence is available to support or refute most established EMS practices, new interventions, or novel EMS programs. To improve this, participants outlined recommendations to increase the amount and rigour of Canadian EMS research. Four key messages emerged from these recommendations. The first is the importance of fostering research partnerships and increasing opportunities for linkages and teamwork across the spectrum of EMS research stakeholders (e.g., academic centres, systems, regulators, education institutions, and national associations). The second key message is the need for further research education for those who work in EMS. Providers, physicians, administrators, and educators were identified as requiring more education on research literacy and process, starting at the entryto-practice level and continuing throughout all career pathways. The third key message was to embed research culture within the EMS organization to encourage EMS systems to plan, participate in, and 


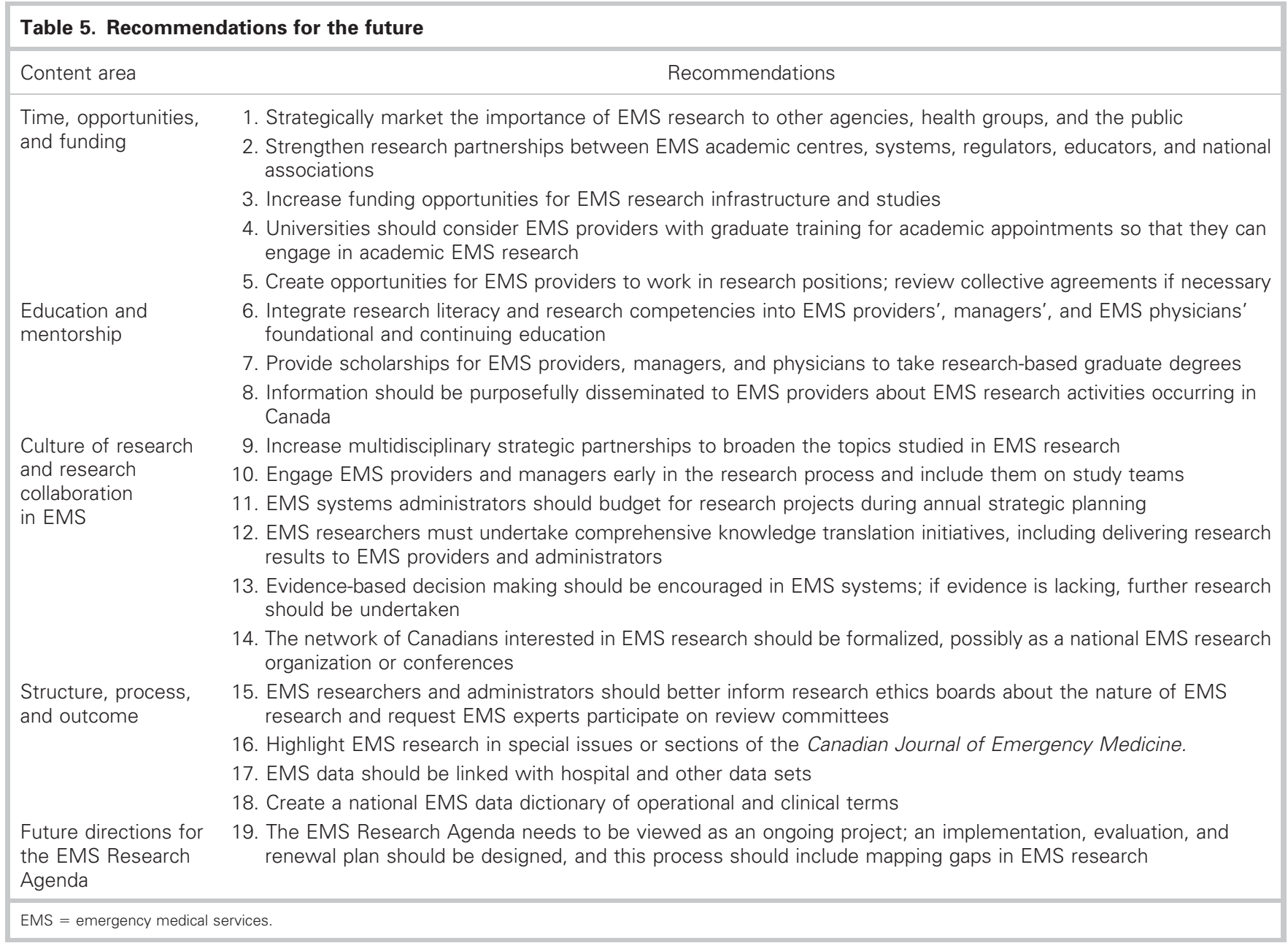

use the results of research. Finally, the last key message relates to the importance of EMS research data. EMS data must be valid and reliable within individual systems and between areas of Canada, and linkages to patient outcome data must be routinely available to EMS administrators and researchers to enable datadriven decisions.

The key messages from this Canadian study echo many of the recommendations made from the United States, Australia, and Ireland. ${ }^{10-14,19,20}$ The outcomes of the Canadian agenda were not, however, identical to those previously published. For example, three of the agendas (United States, United Kingdom, and Ireland) reported barriers to EMS research, ${ }^{10,11,20}$ differing from those found in Canada. The Canadian EMS Research Agenda reported that few EMS research jobs or little salary support is available (see Table 2, number 2 ) and identified a lack of mentorship opportunities available for EMS research (number 4). Similarly, Canadian recommendations included the need to market the importance of EMS research (see Table 5, number 1), strengthening research partnerships (number 2), direct dissemination of research results to EMS providers (number 8), engaging EMS providers and managers early in the research process (number 10), and highlighting EMS research in the Canadian fournal of Emergency Medicine, the national emergency medicine peer-reviewed journal (recommendation number 16). Some EMS research agendas were not the result of research studies. ${ }^{10,11}$ This difference in methodology may result in broader, more objective stakeholder representation and a more rigorous cataloguing and analysis of the participant's viewpoints.

Topics for future study were suggested (see Table 4). Importantly, the suggested topics should not be viewed as exclusive.

To achieve changes suggested by the participants will require strong leadership from national organizations that are stakeholders in EMS research. Development of national strategies will require 
careful planning and organization. Although this agenda may provide important recommendations, the next step is to determine how best to implement at the national level and what support structures are needed to promote local-level implementation. Continued advancement of EMS research will depend on the actions of individuals and groups, including regulators, administrators, medical leadership, academics, educators, and providers in response to these recommendations.

\section{LIMITATIONS}

At the roundtable session, there were more participants with a primary role as EMS provider or administrator compared to physicians and researchers. This may have been compensated for in the Delphi process, which had better physician representation and allowed participants to add statements. Certain provinces appear to be overrepresented. Any effect this may have had on the conclusions of the agenda were small as the scope of EMS research appears to have been adequately represented by the sample. Some participants had difficulty applying the Likert scale to statements they felt were untrue in their local setting. Participants were reminded that the statement may be true somewhere in Canada and to score accordingly; however, this may have limited local issues to achieve consensus.

\section{CONCLUSION}

The purpose of this study was to identify current barriers, strengths, and opportunities to conducting and using research in Canadian EMS to make recommendations to enhance the development of EMS research in Canada. The resultant consensusbased key messages should inform strategic direction locally and nationally to further advance Canadian EMS research.

Acknowledgements: We would like to gratefully acknowledge the support of the EMS community that participated in any or all aspects of the study. The EMS Research Agenda participants were Dug Andrusiek (BC), John Ash (ON), Bud Avery (NS), Emmanuelle Bourdon (QC), Ron Bowles (BC), Dr. Ed Cain (NS), Dr. Jim Christenson (BC), Michel Courtois (QC), Jaclyn Day (ON), Claude Desrosiers (QC), Ingrid Devries (ON), Zach Dewar (NS), Gerard Dinn (YT), Dr. Steve Donaldson (AB), Becky Donelon (AB), Dr. Shaun Dowling (AB), Susan Dugas (NB), Greg Furlong (ON), Ralph Hofmann (ON), Chris Hood (NB), Siobian Kennedy (ON), Trevor Lang (ON), Ron Laverty
(ON), Ryan Lee (AB), Michael Longeway (ON), Ken Lusiak (SK), Dr. Russell MacDonald (ON), Alexander MacQuarrie (NB), Dr. Jennifer McVey (NS), Dr. Rose Mengual (NL), Dr. David Petrie (NS), Pierre Poirier (ON), Richard Poon (AB), Jodi Possia (MB), Michel Ruest (ON), Dr. Eli Segal (QC), Kristy Smaggus (ON), Dr. Sunil Sookram (AB), Dr. Ian Stiell $(\mathrm{ON})$, Walter Tavares (ON), John Trickett (ON), Dr. Christian Vaillancourt (ON), Mark Walker (NS), Dr. Karen Wanger (BC), and Dr. Michelle Welsford (ON). We would also like to thank Dr. Ed Cain and Dr. Andy Anton for their contributions to study design, Jane Helleur (NL) for her professional facilitation of the roundtable session, and Gary Wingrove $(\mathrm{MN})$ and Dr. Peter O'Meara (Australia) for their assistance in facilitating the roundtable.

Competing interests: The Canadian National EMS Research Agenda is a collaborative project of the EMS Chiefs of Canada and the Paramedic Association of Canada, both of which provided study funding. Funding was also provided by the Canadian Institutes of Health Research (KPE-112496), the Nova Scotia Health Research Foundation (PSO-REDI-20107142), the Canadian Police Research Centre (W7714-125453), and the Calgary EMS Foundation.

\section{REFERENCES}

1. Shah MN. The formation of the emergency medical services system. Am 7 Public Health 2006;96:414-23, doi:10.2105/ ÂJPH.2004.048793.

2. Paramedic Association of Canada. National Occupational Competency Profile. 2011. Available at: http://paramedic.ca/ nocp/ (accessed April 13, 2012).

3. Maio RF, Garrison HG, Spaite DW, et al. Emergency medical services outcomes project I (EMSOP I): prioritizing conditions for outcomes research. Ann Emerg Med 1999;33: 423-32, doi:10.1016/S0196-0644(99)70307-0.

4. Callaham M. Quantifying the scanty science of prehospital emergency care. Ann Emerg Med 1997;30:785-90, doi:10. 1016/S0196-0644(97)70049-0.

5. Cone DC. Knowledge translation in the emergency medical services: a research agenda for advancing prehospital care. Acad Emerg Med 2007;14:1052-7.

6. Bigham BL, Aufderheide TP, Davis DP, et al. Knowledge translation in emergency medical services: a qualitative survey of barriers to guideline implementation. Resuscitation 2010;81:836-40, doi:10.1016/j.resuscitation.2010.03.012.

7. Division of Emergency Medical Services, Dalhousie University. Canadian Prehospital Evidence Based Protocols Project. Available at: http://emergency.medicine.dal.ca/ ehsprotocols/protocols/toc.cfm (accessed April 13, 2012).

8. Myers JB, Slovis CM, Eckstein M, et al. Evidence-based performance measures for emergency medical services systems: a model for expanded EMS benchmarking. A statement developed by the 2007 consortium U.S. metropolitan municipalities' EMS medical directors. Prehosp Emerg Care 2008;12:141-51, doi:10.1080/10903120801903793.

9. Emergency Medical Services Chiefs of Canada. The future of EMS in Canada: defining the new road ahead 2006. Available 
at: http://www.emscc.ca/docs/EMS-Strategy-Document.pdf (accessed April 13, 2012).

10. Tippett V, Clark M, Woods S, et al. Towards a national research agenda for the ambulance and pre-hospital sector in Australia. 7 Emerg Prim Health Care 2003;1(1):8p.

11. Sayre MR, White LJ, Brown LH, et al. National EMS research agenda. Prehosp Emerg Care 2002;6(3 Suppl):S1-43, doi:10.3109/10903120209102681.

12. Sayre MR, White LJ, Brown LH, et al. The national EMS research strategic plan. Prehosp Emerg Care 2005;9:255-66, doi:10.1080/10903120590962238.

13. Sayre MR, White LJ, Brown LH, et al. National EMS research agenda: proceedings of the Implementation Symposium. Acad Emerg Med 2003;10:1100-8, doi:10.1111/ j.1553-2712.2003.tb00582.x.

14. Sayre MR, White LJ, Brown LH, et al. The National EMS Research Agenda executive summary. Ann Emerg Med 2002; 40:636-43, doi:10.1067/mem.2002.129241.

15. Committee on the Future of Emergency Care in the United States Health System. Emergency medical services: at the crossroads. Washington (DC): National Academies Press; 2007.

16. National Registry of Emergency Medical Technicians. NREMT EMS Research Fellowship. The Registry 2004; (Spring):3 .

17. National Highway Traffic Safety Administration. Pilot of prehospital evidence-based guideline implementation process. 2011. Available at: https://www.fbo.gov/index?s=opportunity\& mode $=$ form\&id $=2 \mathrm{ccc} 109 \mathrm{fbd} 8 \mathrm{e} 55733 \mathrm{~d} 6256 \mathrm{a} 0 \mathrm{adc} 5 \mathrm{e} 6 \mathrm{f} 7 \& \mathrm{tab}=$ core\&_cview $=0$ (accessed April 13, 2012).

18. Lerner EB, Mosesso V Jr, Zak C. Implementation of research in the out-of-hospital setting. Prehosp Emerg Care 2002;6(2 Suppl):S24, S27-24, S27.

19. Snooks H, Evans A, Wells B, et al. What are the highest priorities for research in emergency prehospital care? Emerg Med 7 2009;26:549-50, doi:10.1136/emj.2008.065862.
20. Centre for Prehospital Research, University of Limerick. $A$ national prehospital research strategy. 2008. Available at: http:// www2.ul.ie/pdf/358997750.pdf (accessed April 13, 2012).

21. Jensen JL, Blanchard IE, Bigham BL, et al. Methodology for the development of a Canadian National EMS research agenda. BMC Emerg Med 2011;11:15, doi:10.1186/1471227X-11-15.

22. Keeney S, Hasson F, McKenna H. The Delphi technique in nursing and bealth research. West Sussex (UK): John Wiley and Sons; 2011.

23. Powell C. The Delphi technique: myths and realities. 7 Adv Nurs 2003;41:376-82, doi:10.1046/j.1365-2648.2003.02537.x.

24. Beattie E, Mackaway-Jones K. A Delphi study to identify performance indicators for emergency medicine. Emerg Med $\mathcal{F}$ 2004;21:47-50, doi:10.1136/emj.2003.001123.

25. Hasson F, Keeney S, McKenna H. Research guidelines for the Delphi survey technique. 7 Adv Nurs 2000;32:1008-15.

26. Boulkedid R, Abdoul H, Loustau M, et al. Using and reporting the Delphi method for selecting healthcare quality indicators: a systematic review. PLoS ONE 2011;6:e20476, doi:10.1371/journal.pone.0020476.

27. Keeney S, Hasson F, McKenna H. Consulting the oracle: ten lessons from using the Delphi technique in nursing research. F Adv Nurs 2006;53:205-12, doi:10.1111/j.13652648.2006.03716.x.

28. Bogdan RC, Biklen SK. Qualitative research in education: an introduction to theory and methods. Boston: Allyn \& Bacon; 2006.

29. Farmer T, Robinson K, Elliott SJ, et al. Developing and implementing a triangulation protocol for qualitative health research. Qual Health Res 2006;16:377-94, doi:10.1177/ 1049732305285708 .

30. O'Cathain A, Murphy E, Nicholl J. Research methods \& reporting: three techniques for integrating data in mixed methods studies. BMF 2010;341:1147-50, doi:10.1136/ bmj.c4587. 